\title{
The ATLAS Superconducting Magnet System: Status of Construction \& Installation
}

\author{
Herman H. J. ten Kate
}

\begin{abstract}
The ATLAS High Energy Physics Experiment at the Large Hadron Collider at CERN is equipped with a hybrid system of four superconducting magnets. A Central Solenoid provides the magnetic field for the inner detector while 2 End-cap Toroids and a Barrel Toroid generate the magnetic field for the muon detectors. The magnet system has a stored energy of $1.6 \mathrm{GJ}$ and is sized $22 \mathrm{~m}$ in diameter and $26 \mathrm{~m}$ in length. Construction of the magnets started in 1998 and will continue until summer 2006 with the completion of the integration and test of the last coils on surface. Currently, in September 2005, all magnet parts were manufactured and delivered to the integration site at CERN. The 8 coils for the Barrel Toroid were completed and successfully tested while the integration of both End Cap Toroids is progressing well. The Barrel Toroid and the Central Solenoid are already installed in the ATLAS cavern $100 \mathrm{~m}$ underground. Tests of the magnets underground will start in autumn 05 after completion of the connections to the vacuum system, He cryogenics and power converters.
\end{abstract}

Index Terms-Cryogenics, magnets, particle detector, solenoid, superconductors, toroids.

\section{INTRODUCTION}

A TLAS is a general-purpose particle detector presently under construction and is equipped to analyze proton-proton collisions up to $14 \mathrm{TeV}$ level provided by the Large Hadron Collider at CERN starting in year 2007. Fig. 1 shows the schematic layout of the LHC and its 2 largest high energy physics experiments including ATLAS. The magnet system of the LHC is located in a tunnel $100 \mathrm{~m}$ underground and at intersection point 1 ATLAS is being built up. Fig. 2 shows the general layout of ATLAS including the main sub-detectors and the 4 superconducting magnets. For bending the collision products and to allow momentum measurements magnetic field in a detector space of about $8000 \mathrm{~m}^{3}$ is required. For this purpose ATLAS is equipped with a hybrid system of 4 large superconducting magnets: a Central Solenoid (CS) providing 2 $\mathrm{T}$ axial magnetic field used by the central trackers, and a Barrel Toroid (BT) and two End-Cap Toroids (ECT), which make the tangential magnetic field of about $1 \mathrm{~T}$ at the muon detectors.

In Table I the main parameters of the 3 toroids and the solenoid are listed. More general features and overviews are published elsewhere [1]-[3] .

Manuscript received September 20, 2005. This work was supported by the ATLAS Collaboration, a collaboration of about 151 laboratories and funding agencies from 34 countries building up the Particle Physics Experiment ATLAS at the LHC located at CERN, Geneva, Switzerland.

The author is the ATLAS Magnet Project Leader and is with the European Organization for Nuclear Research (CERN), Geneva 23, Switzerland (e-mail: herman.tenkate@cern.ch).

Digital Object Identifier 10.1109/TASC.2006.871348

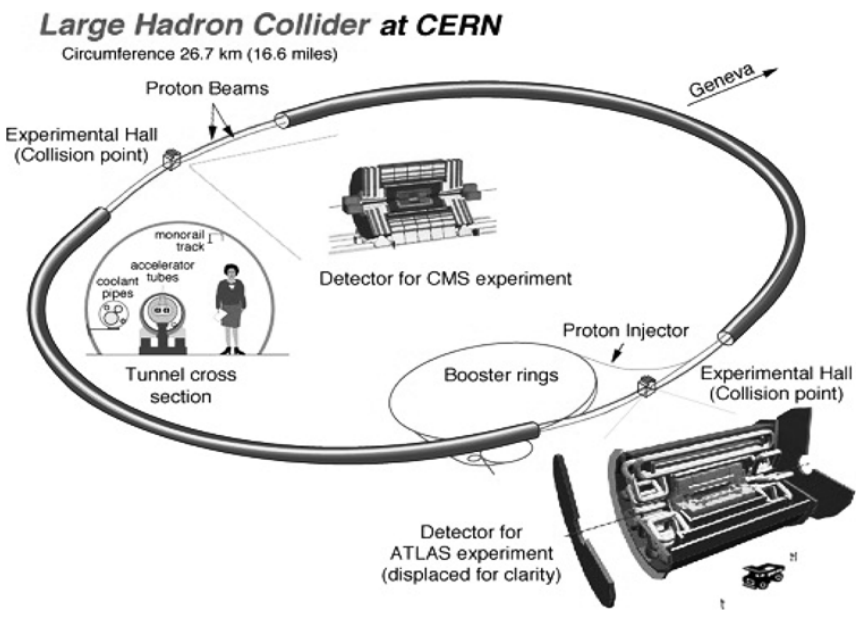

Fig. 1. Schematic view of the Large Hadron Collider (LHC) with its 2 large high energy physics experiments CMS and ATLAS.

The first manufacturing contract was placed in November 1997 for the delivery of superconductor and the last coil modules for the End Cap Toroids arrived in spring 2005 at CERN. Eight years of construction in industry is succeeded by a four year period of integration and on-surface tests and a four years period for installation in the underground cavern, which will end in spring 2007 with an overall system test.

\section{STATUS OF CONSTRUCTION}

The Central Solenoid, which is $5.3 \mathrm{~m}$ long and has a $2.4 \mathrm{~m}$ wide bore, generates $2 \mathrm{~T}$ at $7600 \mathrm{~A}$. The coil was engineered by KEK [4], [5]. It is a single layer coil made with a doped (for higher yield strength) Al stabilized $\mathrm{NbTi} / \mathrm{Cu}$ rectangular conductor, wound on its thin edge inside a $12 \mathrm{~mm}$ thin Al 5083 support cylinder. At the test in the factory the coil achieved 8400 A [8]. After shipment to CERN the coil was integrated with its final cryostat (Fig. 3). The coil underwent the on-surface acceptance test in its final configuration successfully in July 2004 [6]. The coil showed 2 training quenches during the in-factory test at 92 and $99 \%$ of the nominal current of $7600 \mathrm{~A}$ and then went to the maximum test current of $8400 \mathrm{~A}$. After shipment, at the on-surface test at CERN it re-trained at 105 and $107 \%$ of the nominal current [7]. This margin is sufficient for acceptance and the solenoid was installed in the ATLAS cavern in October 2004.

At either side of the Solenoid and in the bore of the Barrel Toroid, two End Cap Toroids are positioned. An End Cap Toroid has a cold mass, which consists of 8 coil modules sized $5 \times$ $5 \mathrm{~m}^{2}$ and kept in position by 8 keystone boxes (Fig. 4). Apart from the windings it is an all $\mathrm{Al}$ structure. The cold mass when 


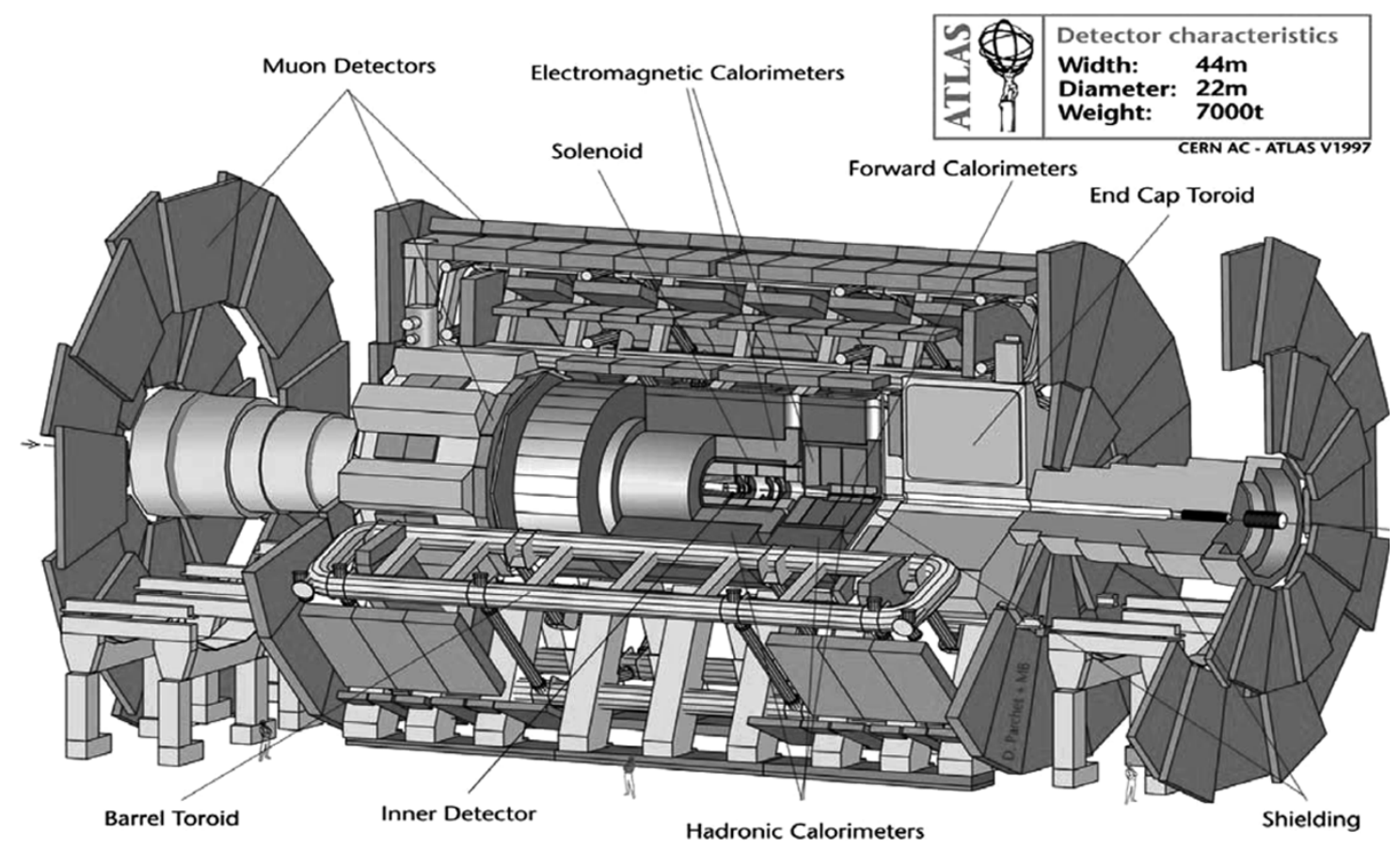

Fig. 2. Schematic view of the ATLAS detector showing the four superconducting magnets: Central Solenoid, 2 End Cap Toroids and the Barrel Toroid. The overall sizes are $26 \mathrm{~m}$ in length by $20 \mathrm{~m}$ in diameter. ATLAS is installed at CERN $100 \mathrm{~m}$ underground at LHC point 1 .

TABLE I

Main Design Paramaters of THE MAGNETS

\begin{tabular}{|c|c|c|c|c|}
\hline Property & Unit & $\begin{array}{l}\text { Barrel } \\
\text { Toroid }\end{array}$ & $\begin{array}{l}\text { End cap } \\
\text { Toroids }\end{array}$ & $\begin{array}{l}\text { Central } \\
\text { Solenoid }\end{array}$ \\
\hline Inner diameter & $\mathrm{m}$ & 9.4 & 1.65 & 2.46 \\
\hline Outer diameter & $\mathrm{m}$ & 20.1 & 10.7 & 2.63 \\
\hline Axial Length & $\mathrm{m}$ & 25.3 & 5 & 5.3 \\
\hline Number of Coils & -- & 8 & $2 \times 8$ & 1 \\
\hline Conductor & $\mathrm{t}$ & 118 & $2 \times 20.5$ & 3.8 \\
\hline Cold mass & $t$ & 370 & $2 \times 160$ & 5.4 \\
\hline Total assembly & $t$ & 830 & $2 \times 239$ & 5.7 \\
\hline Turns /coil & -- & 120 & 116 & 1173 \\
\hline Nominal current & $\mathrm{kA}$ & 20.5 & 20.5 & 7.6 \\
\hline Magnet stored energy & GJ & 1.08 & $2 \times 0.25$ & 0.04 \\
\hline Peak Field & $\mathrm{T}$ & 3.9 & 4.1 & 2.6 \\
\hline Conductor: overall size & $\mathrm{mm}^{2}$ & $57 \times 12$ & $41 \times 12$ & $30 \times 4.25$ \\
\hline Ratio Al:Cu:NbTi & -- & 28:1.3:1 & 19:1.3:1 & 15.6:0.9:1 \\
\hline No of strands & -- & 38 or 40 & 40 & 12 \\
\hline Strand diameter & $\mathrm{mm}$ & 1.3 & 1.3 & 1.22 \\
\hline Critical current@5T,4.2K & $\mathrm{kA}$ & 58 & 60 & 20.4 \\
\hline RRR Al & -- & $>800$ & $>800$ & $>400$ \\
\hline I/Ic margin@4.5K & $\%$ & 30 & 30 & 20 \\
\hline Total length & $\mathrm{km}$ & 56 & $2 \times 13$ & 10 \\
\hline Heat Load: & W & $\sim 900$ & $\sim 300$ & $\sim 130$ \\
\hline At $60-80 \mathrm{~K}$ & $\mathrm{~kW}$ & 7.4 & 1.7 & 0.50 \\
\hline Liquid He mass flow & $\mathrm{g} / \mathrm{s}$ & 410 & 280 & $6-20$ \\
\hline
\end{tabular}

fully assembled is positioned in an $11 \mathrm{~m}$ diameter, $5 \mathrm{~m}$ wide $\mathrm{Al}$ vacuum vessel (Fig. 5). The design of the ECT was completed by RAL [9]-[11], the construction of the coil modules [12] and cryostats [13] is supported by NIKHEF.

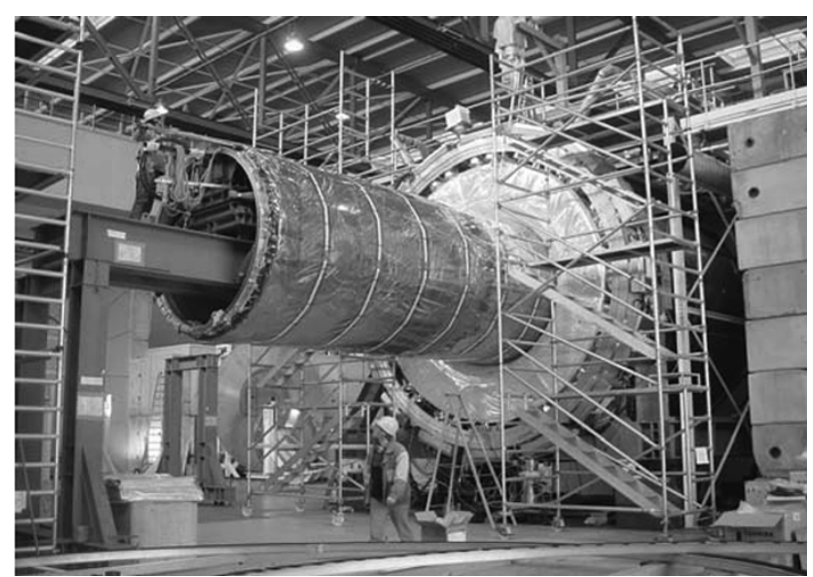

Fig. 3. Central Solenoid in front of the LiAr detector cryostat just before insertion and final on-surface test at CERN.

After shipment to CERN of the vacuum vessels and coil modules the cold mass is assembled on site and inserted in the cryostat [14]. The two End Cap Toroids are being integrated at CERN since Oct 2004 and this activity will be followed by an on-surface test and installation in the cavern in 2006.

The Barrel Toroid (Fig. 6) comprises 8 racetrack coils of $25 \times 5 \mathrm{~m}^{2}$ size. Eight cold masses of windings and Al casings are housed in 8 stainless steel vacuum vessels. The coils are fixed in position in the toroid by an inner and an outer set of 8 support rings made of struts (Fig. 9). Cryogenic connections and bus bars are routed in a cryoring linking the 8 coils. The 830 tons mass of the toroid is taken by 18 feet fixed to the floor of the cavern. The Barrel Toroid was designed by CEA-Saclay with contributions of INFN-LASA and CERN [15]-[17]. The experience with the production of the $90 \mathrm{~km}$ of $\mathrm{Al}$ stabilized 


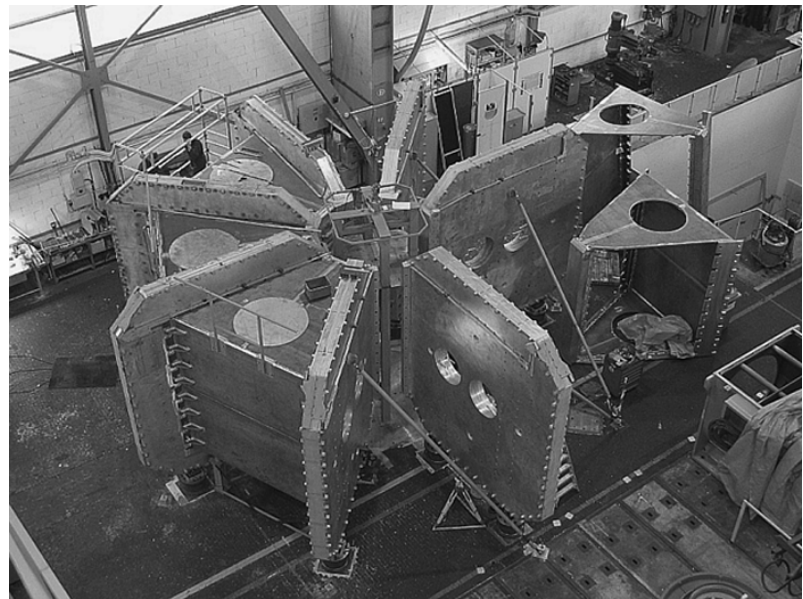

Fig. 4. End Cap Toroid cold mass in the factory, dry assembly of coil modules and keystone boxes before shipment to CERN.

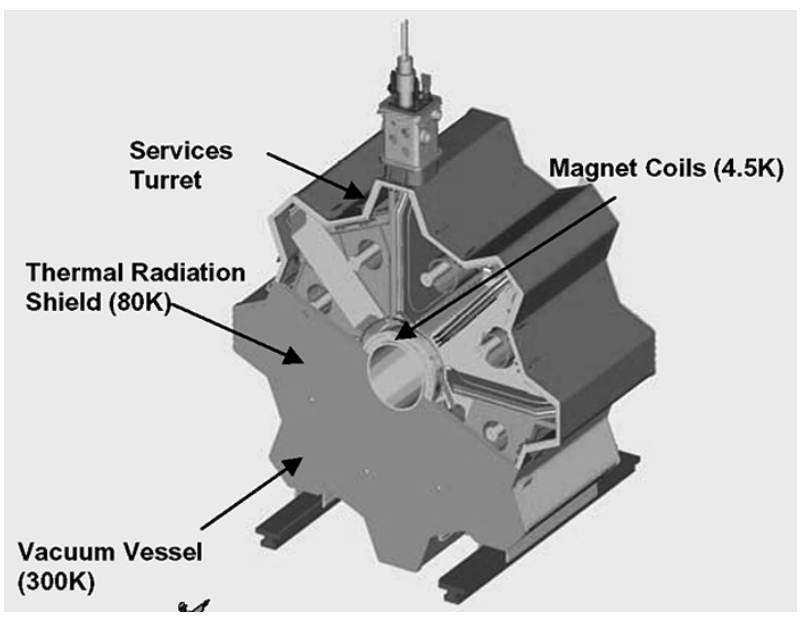

Fig. 5. End Cap Toroid design, showing the essential parts: 8 coils integrated in a single cold mass, surrounded by a radiation shield, built in a vacuum vessel and connected through a services turret.

$\mathrm{NbTi} / \mathrm{Cu}$ conductor produced by two suppliers was summarized [18]. After coil winding in industry, the 16 double pancakes arrived at CERN where the cold mass and cryostat integration took place. The cold mass integration includes the insertion under pre-stress of 2 double pancakes in the Al coil casing [19]. Cryostat integration [20] comprises mounting of cooling circuits, cold mass suspensions (tie rods and lateral stops) [21], installation of thermal shield, super-insulation and instrumentation and finally the insertion in the vacuum vessels. The integration of 8 coils lasted 3 years and was completed in June 05 . In parallel to the integration, the acceptance testing of the coils is performed. A test station with 2 test benches was built [22]. All 8 BT coils underwent an acceptance test up to a maximum current of $22 \mathrm{kA}$ and realistic load. All coils passed the test and were accepted for installation in the cavern. Details of the coil testing like acceptance criteria [23], first coil test [24], summary of all tests [25] and coil ramp losses [26] are reported elsewhere.

After the completion of integration and acceptance tests the coils are ready for transport to the ATLAS cavern (Fig. 7).

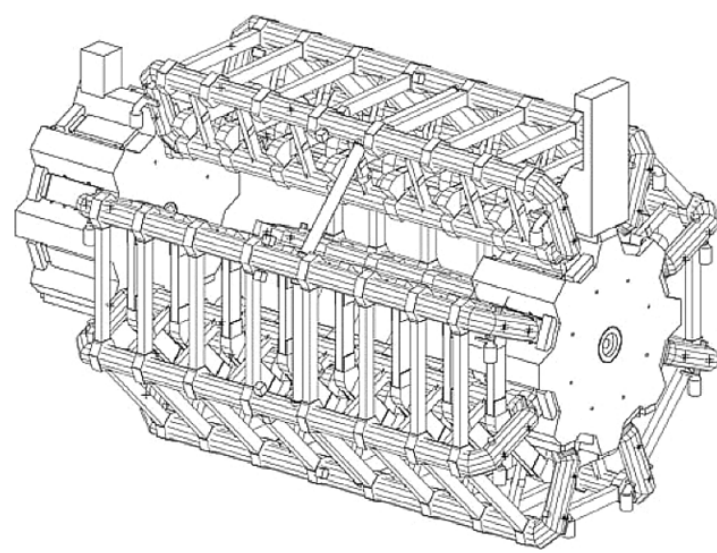

Fig. 6. Schematic view of the Barrel Toroid showing the 8 barrel coils linked by struts, the cryoring for bus bars and cryo-lines and the position of 2 end cap Toroids, one inserted, one retracted.

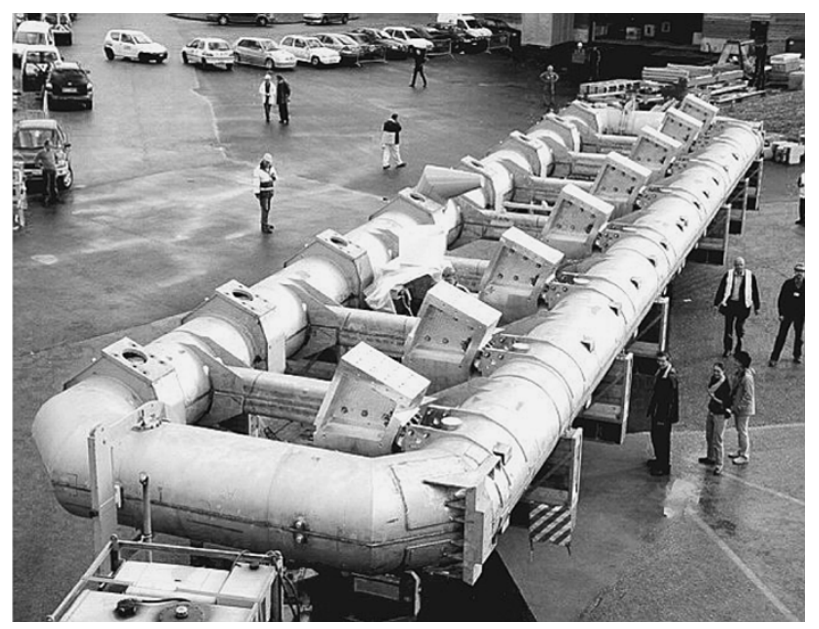

Fig. 7. Barrel Toroid coil transport from integration hall to the surface hall at ATLAS point 1 for descent in the cavern.

\section{MaGnet InStallation In CAVERN}

The Magnet System is installed on stainless steel feet that carry the Barrel Toroid directly and the two End Cap Toroids indirectly via the central rails (see Fig. 2), which enables to retract the two ECT's thereby creating access to the detector interior for maintenance and repairs. Also the Central Solenoid rests on the rail system in the center of the experiment. The Barrel Toroid installation started in Oct 2004 with the insertion of the first coil into the cavern (Fig. 8).

The layout after installation of 6 coils is shown in Fig. 9. The 8 coils are interconnected by the so-called warm structure which comprises a set of 8 inner and 8 outer supporting rings (as can be seen in Figs. 2 and 9). Each ring consists of 8 struts and every strut is assembled between pairs of coils. In total 64 struts and the associated high-strength bolting and shims are required to complete the structure. The struts are typically 5 to $6 \mathrm{~m}$ long and the largest one has a connection flange section of $500 \times 800 \mathrm{~mm}^{2}$. The entire warm structure is made of $\mathrm{Al}$ alloy and produced by stamping, forging and extrusion.

The warm structure design and production features are explained in [28]. 


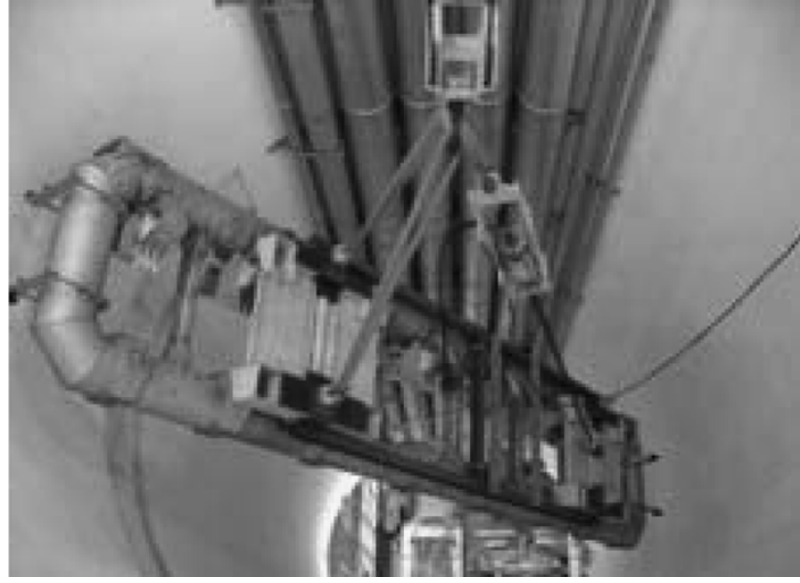

Fig. 8. Descent of a Barrel Toroid coil in the shaft. The $25 \mathrm{~m}$ long coil is inclined to pass the $18 \mathrm{~m}$ wide shaft.

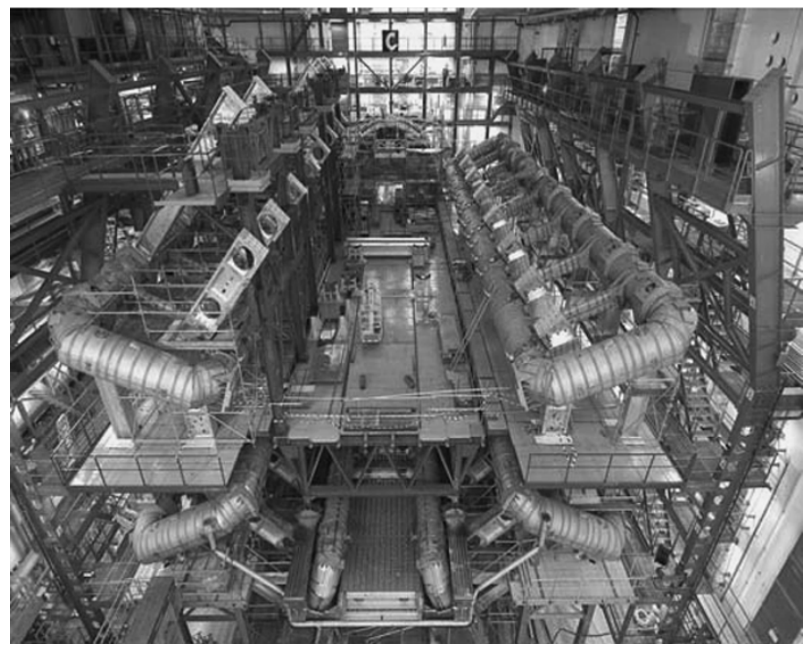

Fig. 9. Barrel Toroid installation in progress (June 2005). Looking into the bore of the toroid, status when 6 coils are in position.

The installation procedure is particular is explained in [29] in detail. The final shape of the toroid bore must be cylindrical but is highly determined by the self weight and other additional loads. To arrive at the desired shape the coils must be positioned in space in a calculated position (egg shape) and fully supported (see the additional structures in Fig. 9). In this stress-free configuration the struts and shims between the coils are measured and put in position. This means in principle the toroid is kept stress-free until the toroid structure is closed. Then the temporary supports are released and the toroid will deflect toward its final cylindrical shape (with $+/-10 \mathrm{~mm}$ tolerance) while taking up the full load. The situation of September 2005, immediately before release of the structure is shown in Fig. 10.

In parallel to the mechanical installation of the toroid, the installation of the interconnections between the coils for transfer of helium lines and bus bars is in progress.

After completion of the Barrel Toroid, the Central Solenoid will be moved on the rails and installed in the center of the experiment (in the center of picture in Fig. 9). Thereafter many sub-detectors have to be installed inside and around the toroid.

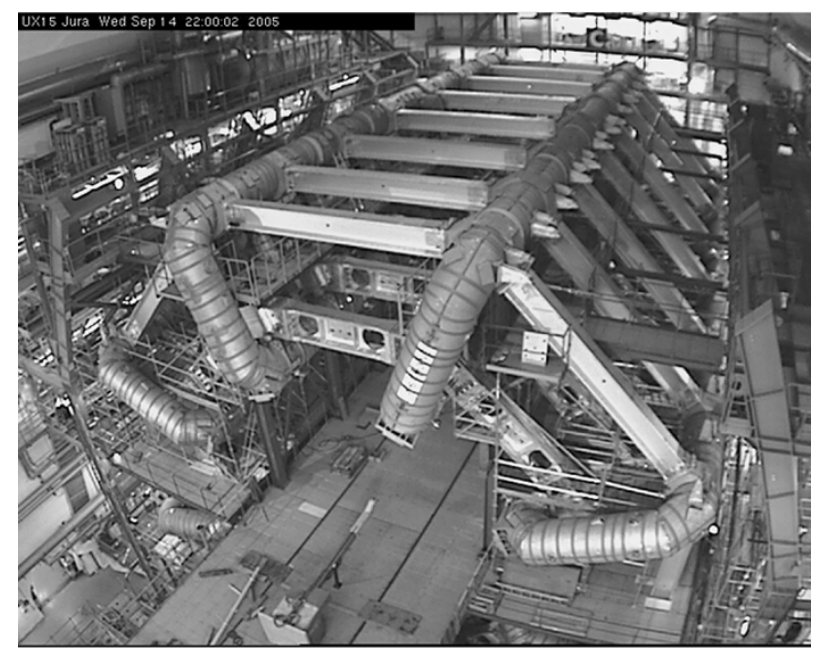

Fig. 10. Barrel Toroid structure in ATLAS cavern completed (Sep 05).

Finally by in autumn 2006 the two End Cap Toroids will be positioned on the rails, thus closing the magnetic structure. The final commissioning test with all magnets present is foreseen for spring 2007, a few months before the entire detector has to be operational.

\section{Current, Helium AND CONTROLS}

In parallel to the installation of the magnets in the cavern, the various services required to operate the system are installed and being commissioned as well [30]. The Barrel and both End Cap Toroids are connected in series to a $24 \mathrm{kA} / 16 \mathrm{~V}$ switch-mode power supply through $200 \mathrm{~m}$ of bus bars and switchgear. Across the BT and the set of ECT's diode/resistor units guarantee safe slow dump of the coils and limit the voltage to $40 \mathrm{~V}$ maximum in the case of a fast dump triggered by a quench. The toroids are charged within $2 \mathrm{hrs}$ with $3 \mathrm{~A} / \mathrm{s}$ and a slow dump takes about the same. Apart from the bus bars near the magnet the electrical system is complete and operational. A similar circuit is present to serve the Solenoid with $8 \mathrm{kA}$ maximum.

The magnets are conduction cooled and two phase helium is circulated through cooling tubes attached to the cold masses. A $6.5 \mathrm{~kW}$ He liquefier, already operational, fills an $11 \mathrm{~kL}$ buffer dewar and from which the helium is taken and circulated by a cold helium pump with $1.3 \mathrm{~kg} / \mathrm{s}$ capacity. A distribution valve box in between pump and coils enables to control the flow in each of the 10 magnet units (8 BT and 2 ECT). A second 60 $\mathrm{kW}$ refrigerator serves the cooling down and keeps the thermal shields at $\sim 50 \mathrm{~K}$. The cryogenic system is presently being commissioned.

The Magnet Control and Magnet Safety System provides the process controls for vacuum, cryogenics, electrical systems and the quench protection system triggering fast dump, respectively.

\section{CONCLUSION}

The realization of the ATLAS Magnet System is progressing well. The production of all coil and cryostat parts in industry has finished. The Solenoid construction is completed, the coils 
fully tested and already installed in the cavern. The construction and on-surface test of the eight huge Barrel Toroid coils are completed as well. Assembly of the Barrel Toroid underground has recently been completed and connections to the magnet services are in progress which will enable the test of the toroid in spring 2006. The last magnets required for installation are the 2 End Cap Toroids, whose integration is now in progress and installation will follow in 2007. The full system test and thereby completion of the largest hybrid magnet system in the world is foreseen for early 2007, a few months before the LHC at CERN will start up and bring us the physics results we expect and, hopefully, far beyond.

\section{ACKNOWLEDGMENT}

The co-workers in the magnet teams at CEA-Saclay (F), RAL (UK), KEK (J), INFN-LASA (I), NIKHEF (NL) and CERN are greatly acknowledged for their continuous effort to make this project a great success.

\section{REFERENCES}

[1] H. H. J. ten Kate, "Superconducting magnet system for the ATLAS detector at CERN," IEEE Tr. Appl. Superconductivity, vol. 9, p. 841, 1999.

[2] — "The superconducting magnet system, for the ATLAS detector at CERN," IEEE Tr. on Appl. Supercond., vol. 10, p. 347, 2000.

[3] _ _ "ATLAS superconducting toroids and solenoid," IEEE Trans. on Applied Superconductivity, vol. 15, no. 2, pp. 1267-1270, 2005.

[4] A. Yamamoto et al., "Design and development of the ATLAS central solenoid," IEEE Trans. on Applied Superconductivity, vol. 9, p. 852, 1999.

[5] — "Progress in the ATLAS central solenoid," IEEE Transactions on Applied Superconductivity, vol. 10, p. 353, 2000.

[6] R. Ruber et al., "ATLAS superconducting central solenoid on-surface test," IEEE Trans. on Applied Superconductivity, vol. 15, p. 12832 , 2005.

[7] R. Ruber, G. Olesen, H. H. J. ten Kate, Y. Makida, M. Kawai, A. Yamamoto, and S. Mizumaki, "Quench characteristics of the ATLAS central solenoid," presented at the Proc. MT19 Conf., Sep. 2005, paper THA08PO03, unpublished.

[8] S. Mizurnaki et al., "Fabrication and mechanical performance of the ATLAS central solenoid," IEEE Tr. Appl. Supercond, vol. 12, p. 415, 2002.

[9] D. E. Baynham et al., "Engineering design of the superconducting end cap toroid magnets for ATLAS," in Proc. MT15, Beijing, Oct. 1997.

[10] _ - "Engineering design optimization of the super-conducting end cap toroid magnets for the ATLAS experiment at LHC," IEEE Trans. on Applied Superconductivity, vol. 9, no. 2, 1999.

[11] _ _ "Eng. status of the end cap toroid magnets for the ATLAS experiment," IEEE Trans. on Appl. Supercond, vol. 10, 2000.

[12] _ _ "ATLAS end cap toroid magnets cold mass design and manufacturing status," IEEE Transactions. on Applied Superconductivity, vol. 14, p. 485, 2004.

[13] $\_$, "ATLAS end cap toroid magnets cryostat design, manufacture and integration at CERN," IEEE Trans. Appl. Superconductivity, vol. 14, p. 522, 2004.
[14] D. E. Baynham, E. Towndrow, S. Carr, E. Holtom, J. Buskop, A. Dudarev, R. Ruber, and H. H. J. ten Kate, "ATLAS end cap toroid cold mass and cryostat integration," presented at the Proc. MT19 Conf., Sep. 2005, paper THA08PO04, unpublished.

[15] A. Dael et al., IEEE Transactions on Magnetics, vol. 32, p. 2047, 1996.

[16] —, in Proc. MT-15, Beijing, China, Oct. 1997.

[17] P. Védrine, F. Alessandria, M. Arnaud, C. Berriaud, R. Berthier, A. Dudarev, A. Leone, B. Levesy, C. Mayri, Y. Pabot, J.-M. Rey, L. Z. Sun, H. H. J. ten Kate, G. Volpini, and Y. Zaitsev, "Manufacturing and integration progress of the ATLAS barrel toroid magnet at CERN," IEEE Trans. Appl. Supercond, vol. 14, no. 2, pp. 491-494, 2004.

[18] G. Volpini, G. Baccaglioni, G. Cartegni, D. Pedrini, E. Baynham, C. Berriaud, B. Blau, I. L. Horvath, and H. H. J. ten Kate, "Production review of $85 \mathrm{~km}$ of Al-stabilized NbTi cable for the ATLAS toroids," presented at the Proc. MT19 Conf., Sep. 2005, paper TUA01PO02, unpublished.

[19] J.-M. Rey, M. Arnaud, C. Berriaud, S. Cazaux, M. Humeau, R. Leboeuf, C. Mayri, P. Vedrine, A. Dudarev, and H. H. J. ten Kate, "Cold mass integration of the ATLAS barrel toroid magnets at CERN," presented at the Proc. MT19 Conf., Sep. 2005, paper THA08PO08, unpublished.

[20] P. N. Vedrine, M. Arnaud, C. Berriaud, B. Levesy, C. Mayri, J. M. Rey, A. Dudarev, H. J. ten Kate, F. Alessandria, and G. Volpini, "Completion of the manufacturing of the ATLAS barrel toroid magnet at CERN," presented at the Proc. MT19 Conf., Sep. 2005, paper WEA3OR3, unpublished.

[21] C. Mayri, P. Vedrine, C. Berriaud, M. Reytier, Y. Pabot, S. Cazaux, A. Foussat, A. Dudarev, Y. Zaitsev, and H. H. J. ten Kate, "Suspension system of the barrel toroid cold mass," presented at the Proc. MT19 Conf., Sep. 2005, paper THA08PO01, unpublished.

[22] P. Miele and H. H. J. ten Kate et al., "The ATLAS magnet test facility at CERN," IEEE Trans. on Appl. Superconductivity, vol. 11, p. 1713, 2000.

[23] C. Berriaud et al., On-Surface Test of the ATLAS Barrel Toroid Coils: Acceptance Criteria and Results this conference.

[24] A. Dudarev et al., "First full-size ATLAS barrel toroid coil successfully tested up to $22 \mathrm{kA}$ at 4 T," IEEE Trans. on Applied Superconductivity, vol. 15 , no. 2, pp. 1271-1275, 2005.

[25] A. Dudarev, J. J. Rabbers, S. Junker, R. Pengo, H. H. J. ten Kate, C. Berriaud, M. Arnaud, P. Vedrine, F. Broggi, and G. Volpini, "On-surface test of the ATLAS barrel toroid coils: overview," presented at the Proc. MT19 Conf., Sep. 2005, paper WEA3OR4, unpublished.

[26] A. Dudarev, J. J. Rabbers, H. H. J. ten Kate, C. Berriaud, and F. Broggi, "Quench behavior of the ATLAS barrel toroid coils," presented at the Proc. MT19 Conf., Sep. 2005, paper THA08PO10, unpublished.

[27] J. J. Rabbers, A. Dudarev, R. Pengo, H. H. J. ten Kate, and C. Berriaud, "Experimental and theoretical investigation of the ramp losses in the conductor and coil casing of the ATLAS barrel toroid coils," presented at the Proc. MT19 Conf., Sep. 2005, paper THA08PO07, unpublished.

[28] Z. Sun, B. Levesy, M. Massinger, C. Mayri, Y. Pabot, P. Vedrine, I. Zaitsev, A. Dudarev, and H. H. J. ten Kate, "ATLAS barrel toroid warm structure design and manufacturing," presented at the Proc. MT19 Conf., Sep. 2005, paper THA08PO021, unpublished.

[29] A. Foussat, M. Raymond, H. J. J. ten Kate, B. Levesy, C. Mayri, P. Vedrine, Z. Sun, and Y. Pabot, "Assembly concept and technology of the ATLAS barrel toroid," presented at the Proc. MT19 Conf., Sep. 2005, paper THA08PO12, unpublished.

[30] P. Miele, F. Cataneo, N. Delruelle, C. Geich-Gimbel, F. Haug, G. Olesen, R. Pengo, E. Sbrissa, H. Tyrvainen, and H. H. J. ten Kate, "ATLAS magnet common cryogenic, vacuum, electrical and control systems," IEEE Trans. Applied Superconductivity, vol. 14, pp. 504-508, 2004 